NASA/TM-2001-210590
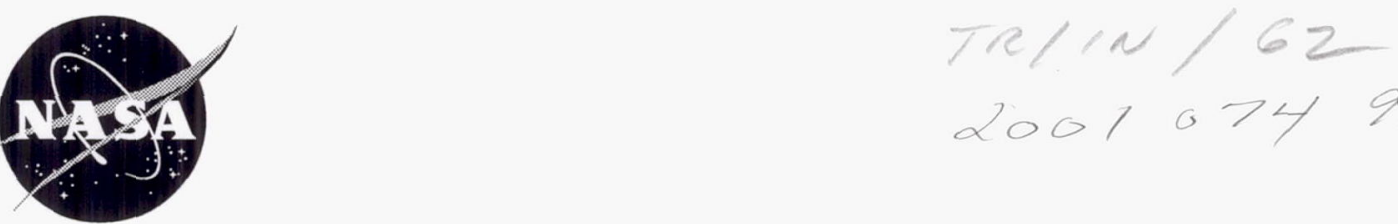

\title{
Application of Mobile-ip to Space and Aeronautical Networks
}

Kent Leung and Dan Shell

Cisco Systems, San Jose, California

William D. Ivancic

Glenn Research Center, Cleveland, Ohio

David H. Stewart

Verizon, Cleveland, Ohio

Terry L. Bell

Lockheed Martin, Cleveland, Ohio

Brian A. Kachmar

Analex Corporation, Brook Park, Ohio 
Since its founding, NASA has been dedicated to the advancement of aeronautics and space science. The NASA Scientific and Technical Information (STI) Program Office plays a key part in helping NASA maintain this important role.

The NASA STI Program Office is operated by Langley Research Center, the Lead Center for NASA's scientific and technical information. The NASA STI Program Office provides access to the NASA STI Database, the largest collection of aeronautical and space science STI in the world. The Program Office is also NASA's institutional mechanism for disseminating the results of its research and development activities. These results are published by NASA in the NASA STI Report Series, which includes the following report types:

- TECHNICAL PUBLICATION. Reports of completed research or a major significant phase of research that present the results of NASA programs and include extensive data or theoretical analysis. Includes compilations of significant scientific and technical data and information deemed to be of continuing reference value. NASA's counterpart of peerreviewed formal professional papers but has less stringent limitations on manuscript length and extent of graphic presentations.

- TECHNICAL MEMORANDUM. Scientific and technical findings that are preliminary or of specialized interest, e.g., quick release reports, working papers, and bibliographies that contain minimal annotation. Does not contain extensive analysis.

- CONTRACTOR REPORT. Scientific and technical findings by NASA-sponsored contractors and grantees.
- CONFERENCE PUBLICATION. Collected papers from scientific and technical conferences, symposia, seminars, or other meetings sponsored or cosponsored by NASA.

- SPECIAL PUBLICATION. Scientific, technical, or historical information from NASA programs, projects, and missions, often concerned with subjects having substantial public interest.

- TECHNICAL TRANSLATION. Englishlanguage translations of foreign scientific and technical material pertinent to NASA's mission.

Specialized services that complement the STI Program Office's diverse offerings include creating custom thesauri, building customized data bases, organizing and publishing research results ... even providing videos.

For more information about the NASA STI Program Office, see the following:

- Access the NASA STI Program Home Page at http://www.sti.nasa.gov

- E-mail your question via the Internet to help@sti.nasa.gov

- Fax your question to the NASA Access Help Desk at 301-621-0134

- Telephone the NASA Access Help Desk at 301-621-0390

- Write to: NASA Access Help Desk NASA Center for AeroSpace Information 7121 Standard Drive Hanover, MD 21076 
NASA/TM-2001-210590

\section{Application of Mobile-ip to Space and Aeronautical Networks}

Kent Leung and Dan Shell

Cisco Systems, San Jose, California

William D. Ivancic

Glenn Research Center, Cleveland, Ohio

David H. Stewart

Verizon, Cleveland, Ohio

Terry L. Bell

Lockheed Martin, Cleveland, Ohio

Brian A. Kachmar

Analex Corporation, Brook Park, Ohio

Prepared for the

2001 Aerospace Conference

sponsored by the Institute of Electrical and Electronics Engineers

Big Sky, Montana, March 10-17, 2001

National Aeronautics and

Space Administration

Glenn Research Center 
Trade names or manufacturers' names are used in this report for identification only. This usage does not constitute an official endorsement, either expressed or implied, by the National Aeronautics and Space Administration.

Available from

NASA Center for Aerospace Information 7121 Standard Drive Hanover, MD 21076

Price Code: A03
National Technical Information Service 5285 Port Royal Road Springfield, VA 22100

Price Code: A03 


\section{Application of Mobile-ip to Space and Aeronautical Networks}

\author{
Kent Leung and Dan Shell \\ Cisco Systems \\ 170 West Tasman Drive \\ San Jose, CA 95134-1706 \\ 408-526-5030 \\ kleung@cisco.com \\ 216-781-0507 \\ dshell@cisco.com \\ William D. Ivancic \\ National Aeronautics and Space Administration \\ Glenn Research Center \\ 21000 Brookpark Road \\ Cleveland, $\mathrm{OH} 44135$ \\ 216-433-3494 \\ wivancic@grc.nasa.gov
}

\author{
David H. Stewart \\ Verizon \\ 21000 Brookpark Road \\ Cleveland, $\mathrm{OH} 44135$ \\ 216-433-9644 \\ David.H.Stewart@lerc.nasa.gov \\ Terry L. Bell \\ Lockheed Martin \\ 21000 Brookpark Road \\ Cleveland, $\mathrm{OH} 44135$ \\ 216-433-2287 \\ Terry.L.Bell@grc.nasa.gov \\ Brian A. Kachmar \\ Analex Corporation \\ 3001 Aerospace Parkway \\ Brook Park, Ohio 44142 \\ 216-433-8655 \\ Brian.A.Kachmar@grc.nasa.gov
}

\begin{abstract}
The National Aeronautics and Space Administration (NASA) is interested in applying mobile Internet protocol (mobile-ip) technologies to its space and aeronautics programs. In particular, mobile-ip will play a major role in the Advanced Aeronautic Transportation Technology (AATT), the Weather Information Communication (WINCOMM), and the Small Aircraft Transportation System (SATS) aeronautics programs. This paper describes mobile-ip and mobile routersin particular, the features, capabilities, and initial performance of the mobile router are presented. The application of mobilerouter technology to NASA's space and aeronautics programs is also discussed.
\end{abstract}

\section{TABLE OF CONTENTS}

\author{
1. INTRODUCTION \\ 2. MOBILE-IP \\ 3. MOBILE ROUTER \\ 4. MOBILE ROUTER FEATURES \\ 5. NASA'S INTERESTS \\ 6. SUMMARY
}

\section{INTRODUCTION}

Cisco Systems and NASA Glenn Research Center under a NASA Space Act Agreement have been performing joint networking research to apply Internet technologies and protocols to space-based communications. As a result of this joint research Cisco Systems developed the mobile router for both the commercial and government markets. This paper discusses the mobile router, including its operation and relevant application areas.

\section{MOBILE-IP}

Unlike dynamic ip assignment, whereby a new connection has to be established for each subnetwork, mobile-ip [1] is a routing protocol that allows hosts (and networks) to seamlessly "roam" among various ip subnetworks. Roaming is essential in many wireless networks. Mobile-ip can also be useful in wireless networks where the mobile node's point of attachment to the network is changing as a result of varying conditions in the wireless medium, even if the mobile node is not physically moving. Mobile-ip can also be used in a wired network where the mobile node simply wishes to maintain its network identity, since the mobile node is always contacted through association of its home ip address.

There are three basic elements in mobile-ip: the home agent, the foreign agent, and the mobile node. The home agent (HA) is a router on a mobile node's home network that tunnels datagrams for delivery to the mobile node when it is away from home and maintains current location information for the mobile node. The foreign agent (FA) is a router on a mobile node's visited network that provides routing services to the 
mobile node while it is registered. The foreign agent detunnels and delivers datagrams to the mobile node that were tunneled by the mobile node's home agent. For datagrams sent by a mobile node the foreign agent may serve as a default router for registered mobile nodes. The mobile node (MN) is a host or router that changes its point of attachment from one network or subnetwork to another. A mobile node may change its location without changing its ip address; it may continue to communicate with other Internet nodes at any location by using its (constant) ip address, assuming that link-layer connectivity to a point of attachment is available [1].

A mobile node first determines whether it is attached to its home network or to a foreign network by using Internet control message protocol (ICMP) router discover messages. If it is attached to a foreign network, the mobile node determines if a foreign agent is available. If so, the mobile node registers with the foreign agent. The foreign agent notifies the home agent that it has a visitor, and a unidirectional ip tunnel ${ }^{1}$ is established from the home agent to the foreign agent. The home agent now encapsulates all packets destined for the mobile node and tunnels them to the foreign agent. The foreign agent de-encapsulates the packets and forwards them on to the mobile node. Standard ip routing is used to deliver datagrams sent by the mobile node, with the foreign agent as the mobile node's default router.

Figure 1 depicts mobile-ip operation when the mobile node is a single host. In this scenario the corresponding node requests information from the mobile node. The request is sent first to the mobile node's home ip address through the Internet. Thus, the request goes to the home agent. The home agent encapsulates the request in a second ip packet and tunnels that request through the Internet to the foreign agent. The foreign agent de-encapsulates the request and passes it on to the mobile node by using the care-of-address. Once the mobile node receives the request, it sends a reply to the corresponding node through normal ip routing. Thus, the reply goes to the foreign agent, which passes it on to the corresponding node through the Internet.

\section{MobILe Router}

Mobile router (MR) technology is pertinent to a myriad of applications for both the government and commercial sectors. For example, this technology will be applied to the wireless battlefield. NASA and the Department of Defense will use

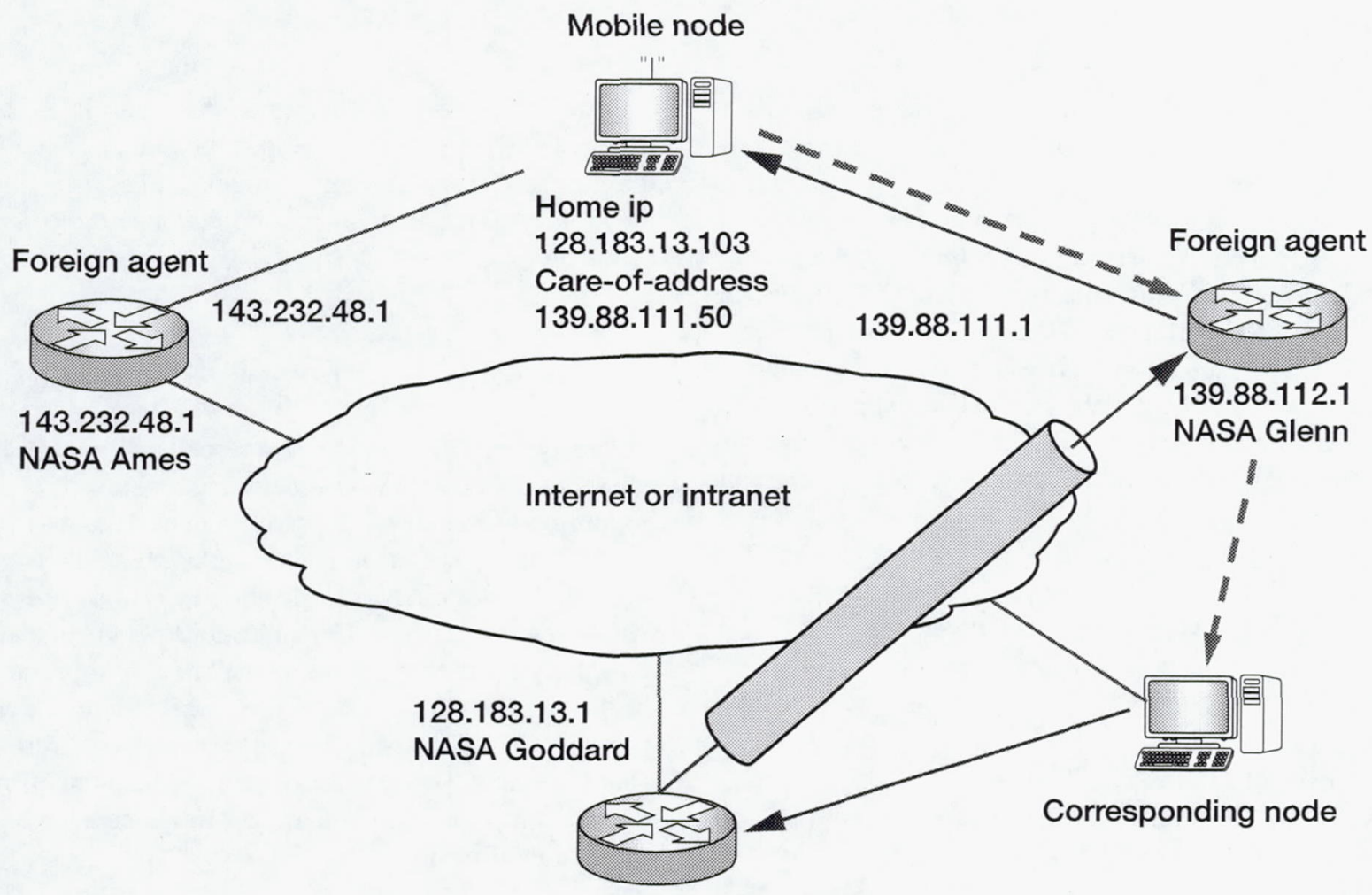

Home agent

Figure 1.-Mobile-ip tunneling.

${ }^{1}$ Tunneling enables one network to send its data through another network's connections. Tunneling works by encapsulating a network protocol within packets carried by the second network. 
this technology for near-planetary observation and for sensing spacecraft. It is the enabling technology for Internet or intranet communications to aircraft. Information such as weather, air traffic control, voice, and video can be easily and inexpensively transmitted to the aircraft by using Internet protocols. The mobile router allows many of NASA's aeronautics programs to become a reality. Such programs include Small Aircraft Transportation System (SATS), Weather Information Communication (WINCOMM), and Advanced Aeronautical Transportation Technology (AATT) Free-Flight. The mobile router will be incorporated into emergency vehiclesparticularly ambulances and life-flight aircraft to provide realtime connectivity back to the hospital and health care experts. Commercial applications include entertainment services, ip telephone, and Internet connectivity for cruise ships, commercial shipping, tour buses, aircraft, and eventually cars.

The mobile router is software code that resides in a network router. It is part of the mobile-ip standards specification. A mobile router allows an entire network (or networks) to roam. Hence, a device connected to the mobile router does not need to be a mobile node, since the mobile router is providing the roaming capabilities.

Cisco Systems has recently implemented mobile router code. NASA Glenn and Cisco, through a Space Act Agreement, have been performing joint research and validation tests on this code, which will become part of Cisco Systems Internetworking Operating System (IOS) in early 2001. The current deployment of the mobile router is for a static network. A static network supports only stub routers.

Mobile router code allows a router to be a mobile node. The difference between a mobile host and a mobile router is that once the mobile router has registered with the home agent, the home agent will inject the mobile router's networks into the home agent's routing table and will redistribute these routes. This implementation is fully compliant with the Request for Comments 2002 standard. No alteration to the specification is necessary to achieve this static networking.

Figure 2 depicts mobile-ip operation when the mobile node is a network. The operation is nearly identical to that of mobileip for a single host. The exceptions are that two tunnels are established: one between the home agent and foreign agent (tunnel-1) and one between the home agent and mobile router (tunnel-0). The home agent performs two encapsulations of any packet destined for the mobile router and forwards all packets for the mobile network to the foreign agent. The foreign agent performs one de-encapsulation and passes the packets to the mobile router. The mobile router performs the second de-encapsulation and forwards the packets to the devices on

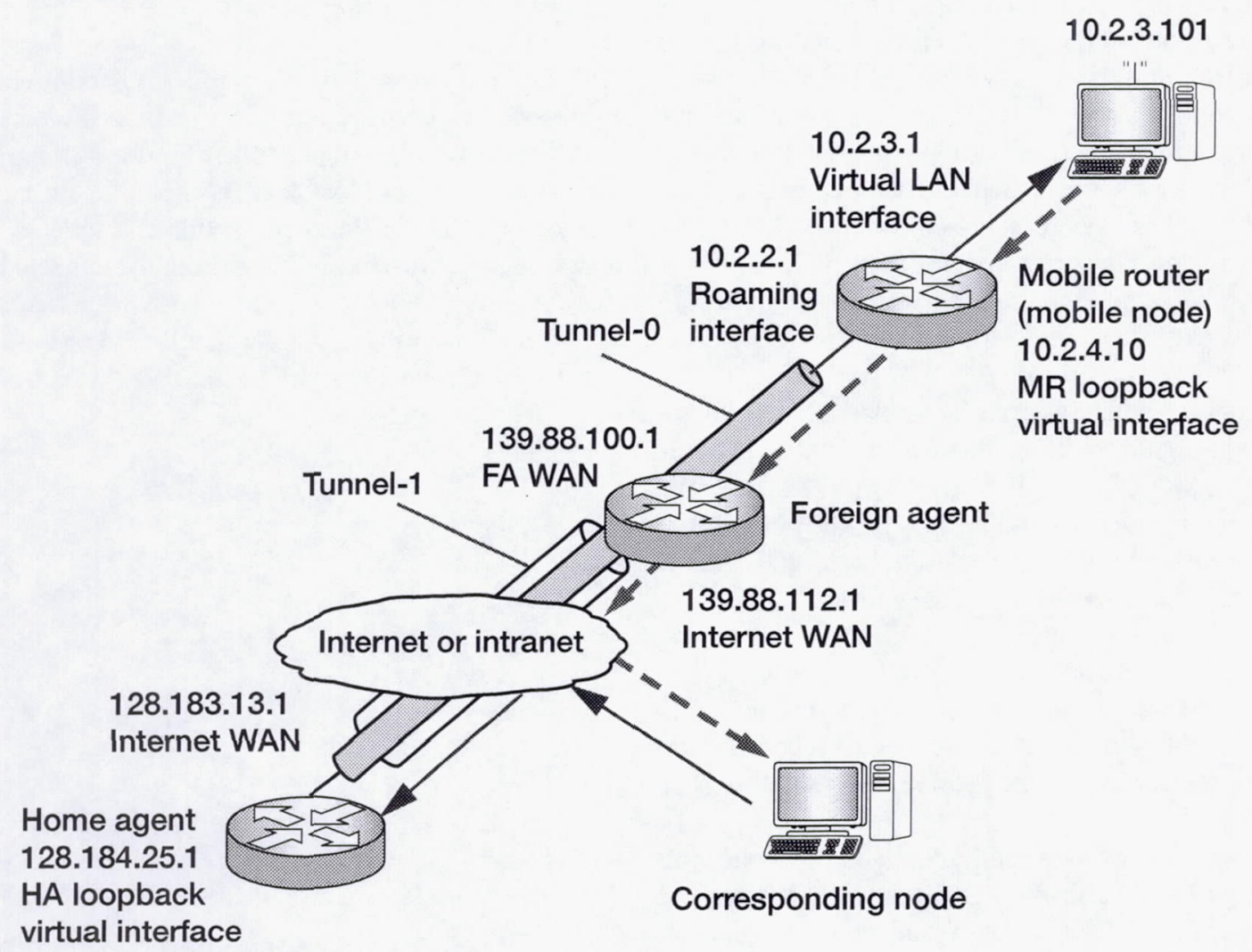

Figure 2.-Mobile router tunneling. 
its networks. As the mobile router moves, it registers with its home agent on its whereabouts by using various foreign agents. Thus, a mobile router is a mobile node; however, the node is a network rather than a single host.

\section{Mobile Router Features}

The mobile router has a number of features that make it applicable to a variety of networks and applications. The mobile router can have multiple roaming interfaces, allowing for connection to a variety of wired and wireless links. One example would be a mobile router residing on an aircraft and having three roaming wide-area-network (WAN) interfaces and two nonroaming local-area-network (LAN) interfaces. One LAN may be for aircraft operations (flight information services, air traffic control, weather, etc.) while the second LAN is reserved for passenger communication and entertainment services. One roaming interface may be a $100 \mathrm{Base}-\mathrm{T}$ interface for a wired connection while at the gate. A second roaming interface may be connected to a very high-frequency data link (VDL) antenna. The third roaming interface may be connected to a satellite antenna.

The mobile router can perform smooth hand-offs, preferred path routing, and priority routing. Consider the aircraft example: The VDL may be active during takeoff. Once in flight both the VDL and the satellite link may be active. The preferred path may be the satellite link, assuming that it has greater bandwidth. In this case the routing will automatically switch from the VDL to the satellite link. If both links are up and the satellite link goes down, the routing will automatically revert back to the VDL. If for some reason one would prefer that the VDL be used (for whatever reason - cost, delay, etc.), it can be set to have a higher priority than the satellite link. Thus, when both links are active, the routing would be by the path with highest priority, the VDL in this example.

The home agent can be configured for hot standby. This feature is extremely important. If the home agent were to experience a catastrophic failure, all routes would be lost. We demonstrated hot standby by pulling the power plug on the active home agent and noting the restoration time. Restoration was nearly instantaneous.

The mobile-routing protocols perform well in long-delay environments. We tested the mobile router's capabilities over links with round-trip time delays in excess of 3 seconds. This delay is far greater than a double, geostationary satellite hop.

As of November 2000 we were still addressing the following areas: Internet protocol security (IPSec ${ }^{2}$ ) between the foreign agent and the mobile router, multicasting, and unidirectional link routing $\left(\mathrm{UDLR}^{3}\right)$. Currently, IPSec does exist between the mobile

${ }^{2}$ The IPSec protocol provides secure, interoperable communications across a network, transparent to the application. router and the home agent. Security can also be implemented between the foreign agent and the home agent by using IPSec and/or by establishing access lists in the home agent.

\section{NASA'S INTERESTS}

NASA is interested in applying commercial-off-the-shelf Internet technology to NASA missions in order to reduce costs while simultaneously upgrading its communications networks. Applying mobile-ip technologies to NASA missions will facilitate these goals. The United States government has numerous applications where mobile-ip is desired: general computing, aeronautical telecommunications networks, orbiting space science missions, and terrestrial science missions (Earth, Moon, Mars, asteroids, etc.).

Mobile-ip is required for spacecraft communicating through a number of ground terminals networked together (assuming duplex communications) when each ground terminal is an independent node on the network. Figure 3 illustrates such a network. As the spacecraft orbits the planet, it often is not connected to any ground terminal, as is the case for time T2. At other times it will come in contact with one or more ground terminals. All registration and routing will automatically occur when using mobile-ip protocols. If the spacecraft has multiple instruments that are ip addressable, the mobile router will apply.

In an aeronautical network mobile-ip is required to maintain connectivity. As the aircraft moves from region to region it is traversing various subnetworks. Figure 4 illustrates an aeronautical network. Note that the home agent can be located anywhere on the Internet. In this example at time T1 the mobile router on the aircraft would be connected to the home agent through the foreign agent FA1-perhaps through an Ethernet link. At time T2 the mobile router is still connected to the home agent through FA1, but now through a VDL, VDLa.

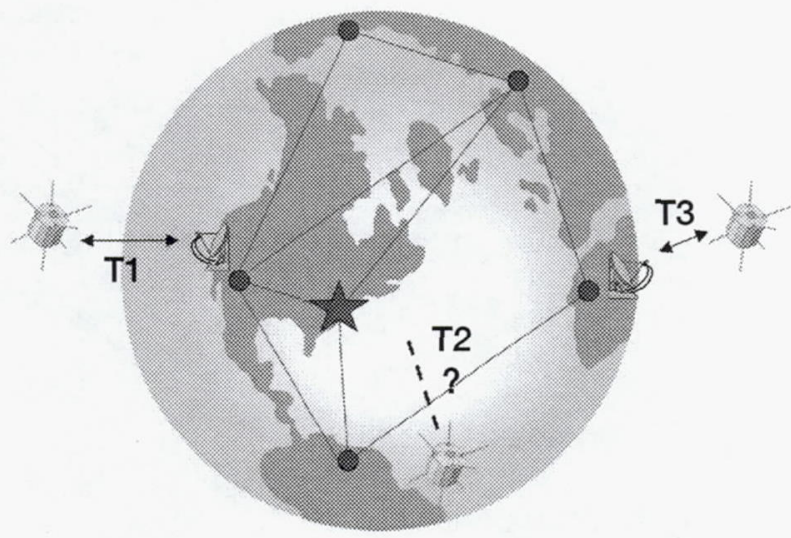

\section{Figure 3.-LEO spacecraft communications network.}

${ }^{3}$ UDLR describes a mechanism to emulate bi-directional connectivity between nodes that are directly connected by a unidirectional link. 


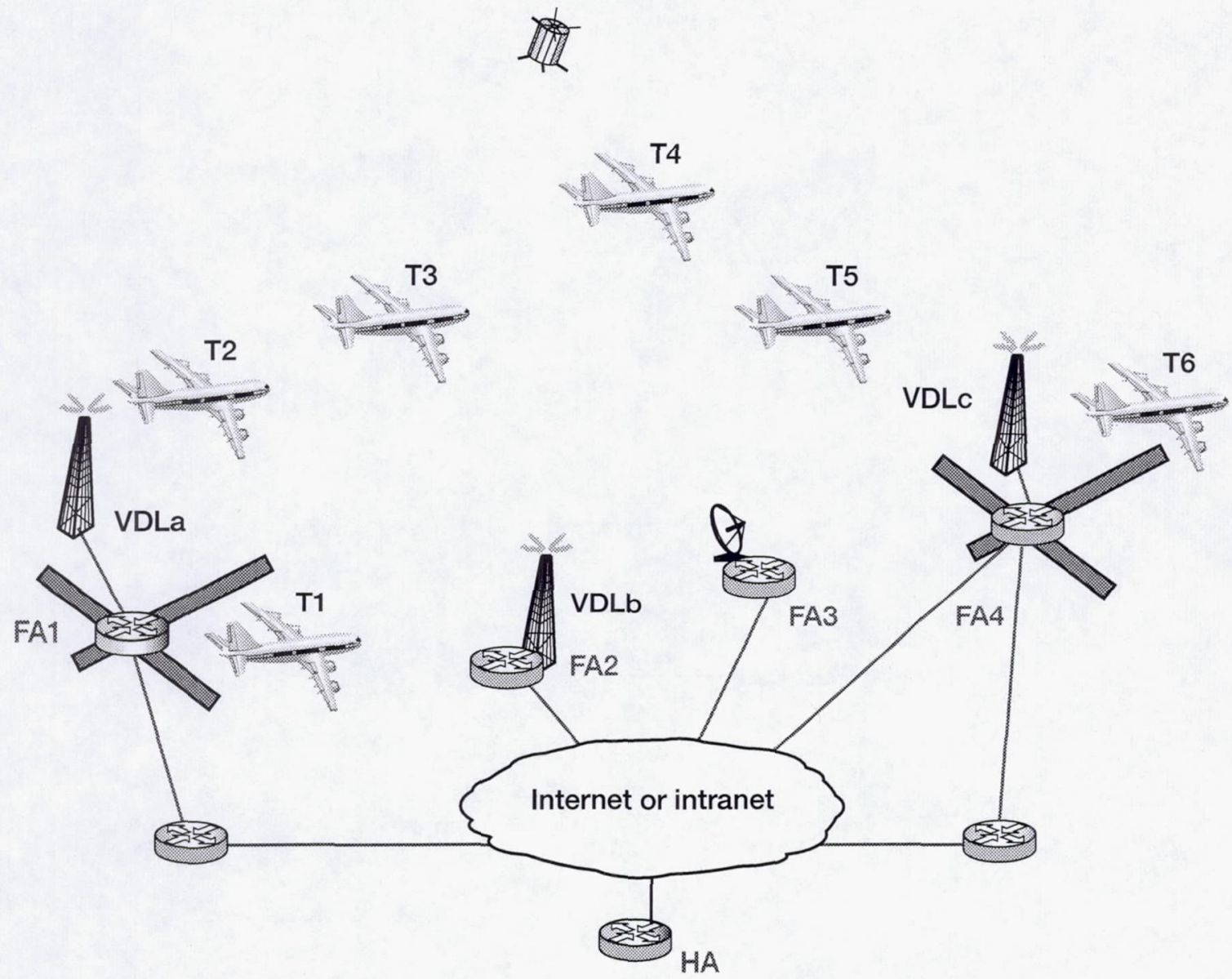

Figure 4.-Aeronautical telecommunications network.

At time T3 the mobile router is connected to the home agent through FA2 and VDLb. At time T4 both the VDLb and satellite communications links may be active. The preferred path may be through FA3 because of the larger available bandwidth. At time T5 the mobile router is connected to the home agent through VDLc with the foreign agent being FA4. Finally, at landing time T6 a connection is established to FA4 through an Ethernet link. ${ }^{4}$

Mobile-ip and the mobile router will play a major role in NASA's aeronautics programs including AATT, WINCOMM, and SATS [2-4]. Each program requires continuous connectivity while dynamically traversing various subnetworks. Figure 5 illustrates what a potential aeronautical network could entail in 2005. Although only the United States is shown here, connectivity will be global. Future aeronautical networks will use whatever wireless networking is available at reasonable cost. Low-, geostationary-, and medium-Earth-orbit (LEO, GEO, and MEO) satellites may be used, as will VDL and perhaps next-generation cellular. Unique, cost-effective techniques will also be deployed. An example would be using GEO direct-broadcast, digital television satellites with data embed-

\footnotetext{
${ }^{4}$ In this scenario foreign agent functionality is enabled on two interfaces for both FA1 and FA4: the Ethernet umbilical cord interface at the gate and the serial interface to the VDL.
}

ded in the Moving Picture Expert Group 2 (MPEG-2) transport streams to transmit data to the aircraft. The return path would be an inexpensive, low-bandwidth, duplex channel. UDLR would be used here.

Under the AATT program NASA is working in alliance with the Federal Aviation Administration to enable increases in capacity, flexibility, and efficiency, while maintaining safety, of aircraft operations within the United States and the global airspace system. The goals are to increase terminal throughput $40 \%$ and to increase en route throughput $20 \%$. Current operations in the National Air System (NAS) are severely constrained by an antiquated air traffic management system supported by a decades-old communications, navigation, and surveillance infrastructure using primarily analog voice communications, radar surveillance, and ground-based navigational aids. Extensive air traffic system delays and gridlock have resulted. A digital airspace infrastructure is needed to meet the bandwidth, latency, security, and integrity requirements of the future free-flight air traffic management system. The mobile router is an enabling technology for such a system.

Weather is a major contributing factor in accidents. It has been documented that weather causes $37 \%$ of accidents for domestic commercial jet traffic and over $50 \%$ for small aircraft. In addition, weather is a factor in over $72 \%$ of air traffic accidents 


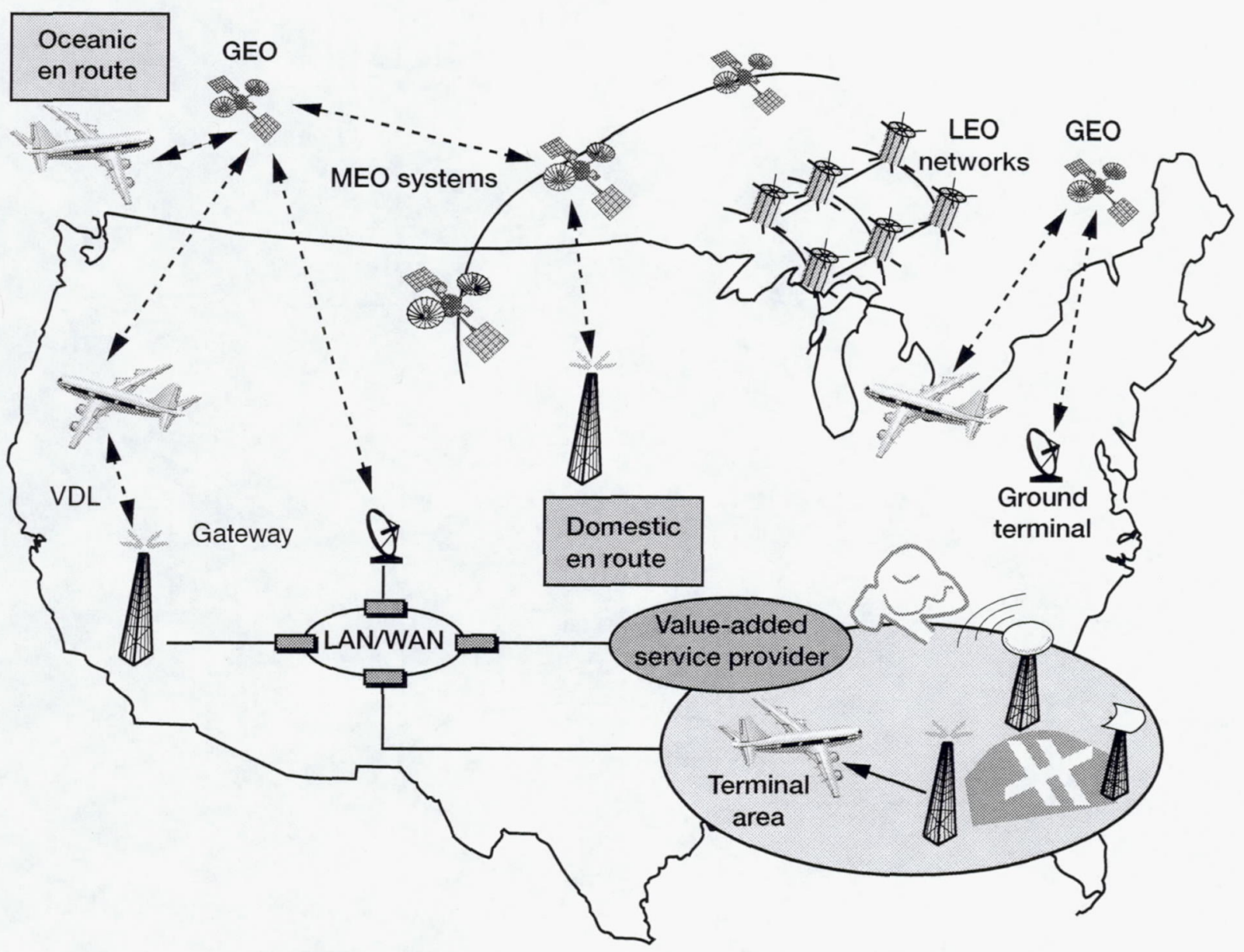

Figure 5.-Command, navigation, and surveillance concept.

internationally [5]. The goal of WINCOMM is to develop advanced communications and information technologies that will enable high-quality aviation weather information and its timely dissemination to all relevant users on the global aviation network. The mobile router, along with multicasting protocols, will play a major role here.

The SATS concept of operations uses small aircraft for pointto-point, direct personal and business travel between smaller regional landing facilities [6]. SATS will offload capacity from the major hubs, which are currently in a state of gridlock. Some of the major elements that need to be developed for SATS are as follows:

1) "Smart" airports with free-flight procedures for expanded NAS capacity

2) Flight information services broadcast by terrestrial or satellite systems

3) Traffic information services, including automatic dependent surveillance, broadcast by aircraft, terrestrial, or satellite systems

4) Destination information services for intermodal connectivity and vehicle and operator/passenger services through terrestrial or satellite systems

5) Near-all-weather operations at nontowered airports without radar coverage
These elements can be made possible by deploying an aeronautical internet with the mobile router as a key technology.

\section{SUMMARY}

The capabilities and characteristics of the mobile router are as follows:

- It enables Internet connections from many types of mobile platform.

- It is software that allows for Networks in Motion.

- It is "set and forget." The configuration needs to be done only once.

- It allows the preferred path to be set by bandwidth or priority.

- It has already implemented many Internet protocol security features.

- A dual hot-standby, mobile router capability has been demonstrated.

- The mobile router is the enabling technology for numerous NASA programs and will be highly used in the aeronautics arena as well as for low-Earth-orbiting Earth observation science platforms. 


\section{REFERENCES}

[1] C. Perkins, ed.: Request for Comments: 2002, Network Working Group, Oct. 1996.

[2] http://wincomm.grc.nasa.gov/about/, 2000.

[3] http://www.asc.nasa.gov/aatt/, 2000.

[4] http://www.unomaha.edu/ unoai/sats/, 2000.

[5] http://www.aerospace.nasa.gov/library/asist/res.htm, 2000.

[6] http://cid.unomaha.edu/ unoai/sats/SATS _ Definition.html, 2000.

Kent Leung is a senior software engineer at Cisco Systems. He was the lead engineer responsible for developing mobileip and mobile router code.

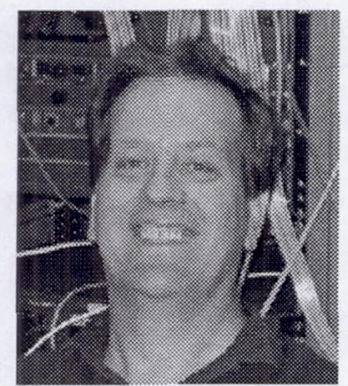

Dan Shell is a senior consulting systems engineer for Cisco Systems, Federal Operations. As the lead engineer in supporting the Cisco/NASA Space Act Agreement for joint network research over high-delay and high-data-rate networks, he has been actively involved with NASA Glenn Research Center in researching ip over satellite and Internet nodes in space. In addition to supporting NASA Glenn, Dan is also responsible for deploying network solutions in the Federal sector-particularly with regard to wireless networks.

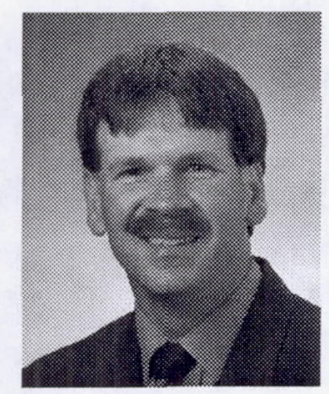

Will Ivancic is a senior research engineer at NASA Glenn Research Center working in networking and advanced communications technology development. His work includes advanced digital and radiofrequency design, communications networks, satellite onboard processing, and system integration and testing. In addition, Will has been responsible for developing proof-of-concept onboard processing satellite equipment, ground terminal equipment, and numerous pieces of special test equipment. His recent research has been directed at applying commencial communications protocols to space and aeronautical networks.

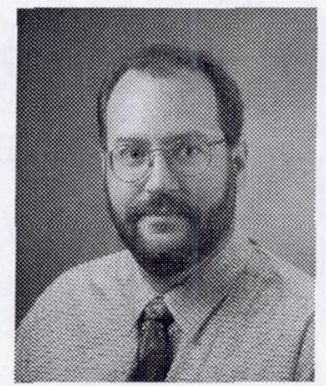

David Stewart is a communications engineer at Verizon. He specializes in radiofrequency and wireless communications networks. For the past 6 years David has supported advanced high-speed networking experiments on NASA's Advanced Communications Technology Satellite (ACTS) including support of the optical carrier 12, high-data-rate terminals. His current work involves developing and deploying a mobile router testbed at Glenn, as well as deploying early-field-trial aeronautical and maritime mobile networks.

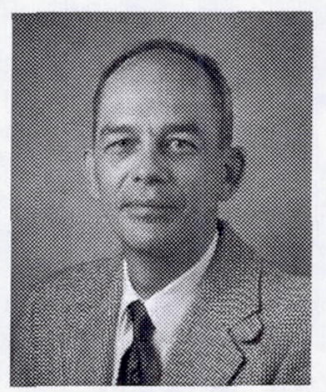

Terry Bell is a telecommunications network specialist for Lockheed Martin Global Telecommunications. Over the past 7 years he has supported ACTS spacecraft operations as well as a variety of satellite networking experiments. His current responsibilities include support of advanced protocol research for space and aeronautical networks.

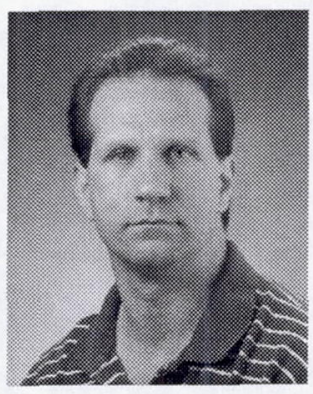

Brian Kachmar is a senior engineer at the Analex Corporation. He supported a myriad of advanced applications research experiments and demonstrations under the ACTS experiments program, including UDLR evaluations, multicasting, and telemedicine. His current interests are in mobile-ip and mobile networks as well as support of research for NASA's aeronautics safety and capacity programs. 
Public reporting burden for this collection of information is estimated to average 1 hour per response, including the time for reviewing instructions, searching existing data sources, gathering and maintaining the data needed, and completing and reviewing the collection of information. Send comments regarding this burden estimate or any other aspect of this collection of information, including suggestions for reducing this burden, to Washington Headquarters Services, Directorate for Information Operations and Reports, 1215 Jefferson Davis Highway, Suite 1204, Arlington, VA 22202-4302, and to the Office of Management and Budget, Paperwork Reduction Project (0704-0188), Washington, DC 20503.
1. AGENCY USE ONLY (Leave blank)
2. REPORT DATE
February 2001
3. REPORT TYPE AND DATES COVERED
Technical Memorandum

4. TITLE AND SUBTITLE

Application of Mobile-ip to Space and Aeronautical Networks

6. AUTHOR(S)

WU-322-20-2A-00

Kent Leung, Dan Shell, William D. Ivancic, David H. Stewart,

Terry L. Bell, and Brian A. Kachmar

7. PERFORMING ORGANIZATION NAME(S) AND ADDRESS(ES)

National Aeronautics and Space Administration

John H. Glenn Research Center at Lewis Field

Cleveland, Ohio 44135-3191

5. FUNDING NUMBERS

National Aeronautics and Space Administration

Washington, DC 20546-0001

8. PERFORMING ORGANIZATION REPORT NUMBER

E-12548

10. SPONSORING/MONITORING AGENCY REPORT NUMBER

NASA TM-2001-210590

11. SUPPLEMENTARY NOTES

Prepared for the 2001 Aerospace Conference sponsored by the Institute of Electrical and Electronics Engineers, Big Sky, Montana, March 10-17, 2001. Kent Leung and Dan Shell, Cisco Systems, 170 West Tasman Drive, San Jose, California 95134-1706; William D. Ivancic, NASA Glenn Research Center; David H. Stewart, Verizon, 21000 Brookpark Road, Cleveland, Ohio 44135; Terry L. Bell, Lockheed Martin, 21000 Brookpark Road, Cleveland, Ohio 44135; and Brian A. Kachmar, Analex Corporation, 3001 Aerospace Parkway, Brook Park, Ohio 44142. Responsible person, William D. Ivancic, organization code 5610, 216-433-3494.

12a. DISTRIBUTION/AVAILABILITY STATEMENT

Unclassified - Unlimited

Subject Categories: 04, 17, 32, and $62 \quad$ Distribution: Nonstandard

Available electronically at http://gltrs.grc.nasa.gov/GLTRS

This publication is available from the NASA Center for AeroSpace Information, 301-621-0390.

13. ABSTRACT (Maximum 200 words)

The National Aeronautics and Space Administration (NASA) is interested in applying mobile Internet protocol (mobile-ip) technologies to its space and aeronautics programs. In particular, mobile-ip will play a major role in the Advanced Aeronautic Transportation Technology (AATT), the Weather Information Communication (WINCOMM), and the Small Aircraft Transportation System (SATS) aeronautics programs. This paper describes mobile-ip and mobile routers - in particular, the features, capabilities, and initial performance of the mobile router are presented. The application of mobile-router technology to NASA's space and aeronautics programs is also discussed.

\begin{tabular}{|c|c|c|c|}
\hline \multicolumn{3}{|l|}{ 14. SUBJECT TERMS } & 15. NUMBER OF PAGES \\
\hline \multicolumn{3}{|c|}{ Satellites; Protocols; Internet } & \begin{tabular}{|c}
13 \\
16. PRICE CODE
\end{tabular} \\
\hline
\end{tabular}

